\title{
"PARA A RELAÇÃO SAPATÔNICA É UM UNIVERSO" A IDENTIDADE DE GÊNERO EM UMA NARRATIVA DE HISTÓRIA DE VIDA
}

Thais Regina Santos Borges é especialista em Língua Inglesa pela PUC-RIO e mestranda em Estudos da Linguagem na PUC-RIO. E-mail: thaisrsborges@gmail.com

\section{Resumo}

O objetivo deste artigo é entender como se dá a socioconstrução de identidade de uma mulher cis lésbica, em um relacionamento estável, implicada pelo Senso Comum e os Sistemas de Coerência aos quais ela recorre em seus posicionamentos. Sob a luz da epistemologia feminista, este artigo reflete acerca da coconstrução de identidade de gênero por meio da análise de uma narrativa de história de vida contada em entrevista qualitativa.

\begin{abstract}
The aim of this article is to understand how the social construction of identity of a cisgender lesbian in a stable relationship occurs, influenced by Common Sense and Coherence Systems she resorts to when positioning herself in her narrative. In the light of feminist epistemology, this article reflects upon the co-construction of gender identity through the analysis of a life story narrative told in a qualitative interview.
\end{abstract}

\section{1) Introdução}

A Linguística Aplicada Crítica, doravante LAC, assim se define por ir além da busca pela compreensão de como a linguagem funciona nas relações humanas em contextos do cotidiano e da compreensão do que podemos fazer para melhorar essas relações, uma vez que foca também no entendimento de como isso se relaciona com as questões de poder, gênero, classe, raça/etnia, etc. (PENNYCOOK, 2015, em palestra). Podemos entendê-la, ainda, como pautada em quatro frentes (e suas respectivas questões): o domínio (efeitos contextuais e contingentes do poder), a disparidade (inequidade de acesso a produtos materiais e culturais), o desejo (identidade, agência, ideologia) e a diferença (diversidade e ambição para transgredir), segundo Pennycook, (2006, p.82-83). Além disso, para estudiosos desse campo, a linguagem em si é definida como um sistema sociossemiótico de produção de significado (CHUN, 2007 apud PENNYCOOK, 2015, em palestra) ou, como "o nosso modo de lidar com as nossas circunstâncias, a nossa sociedade, a nossa inserção dentro da sociedade", uma vez que "tudo no mundo é mediado pela linguagem” (RAJAGOPALAN, 2011', apud SILVA et ali, 2011). É assim que a LAC nos faz um convite para que foquemos em contextos das nossas práticas sociais, ou seja, investigando tanto a esfera pessoal, quanto as esferas educacional e de trabalho.

Com isso em mente, neste trabalho analiso um excertode uma entrevista feita para minha dissertação de mestrado, que tem como objetivo entender como se dá a socioconstrução da identidade de professoras de inglês como língua estrangeira ao lidarem com momentos críticos (PENNYCOOK, 2015, em palestra) que ocorrem na sala de aula, sob uma perspectiva crítico-reflexiva em consonância com a epistemologia feminista interseccional (LYKKE, 2010), situada no campo da LAC. Vale salientar que

SILVA, K. A.; SANTOS, L. I. S.; JUSTINA, O. D. Entrevista com Kanavillil Rajagopalan: ponderações sobre linguística aplicada, política linguística e ensino-aprendizagem. Revista de Letras Norte@mentos - Revista de Estudos Linguísticos e Literários.Edição 08 - Estudos Linguísticos 2011/02. p.02 Disponível em: http://projetos.unemat-net.br/revistas_eletronicas/index.php/norteamentos 
neste artigo minha análise está focada em um excerto em que a professora trata especificamente de uma questão relativa à sua identidade de gênero e não à sala de aula. Ainda dentro da ética da LAC, é essencial compreendermos que para investigarmos esse universo devemos procurar estabelecer um processo crítico-reflexivo substancial com e acerca de mulheres e seus múltiplos perfis, buscando incansavelmente desnaturalizar estereótipos e expectativas. Ao promover encontros com pessoas de diversos backgrounds, não podemos nós, analistas, cair na tentação de achar que vamos a campo "dar voz" a quem quer que seja e devemos evitar sermos tomadas/os pelo espírito e a pretensão da academia “torre-de-marfim”, como alerta Rajagopalan (2006, p.158).

Essa ideia de que a pesquisa em si ou o processo de investigação "dá voz" às pessoas com quem trabalhamos é um equívoco. Quando escolhemos entrar nessa empreitada, "não podemos dar voz, mas ouvimos, sim, vozes que gravamos e interpretamos" (RIESSMAN, 1993, p.8), encarando e confrontando sistematicamente as decisões representacionais que inevitavelmente tomamos de forma a manter a ética e o respeito pelas diferenças entre participantes como um fio condutor. Assim, é preciso celebrar e não neutralizar diferenças culturais (FERREIRA, 2006, p.48) tão caras à melhor compreensão da socioconstrução da identidade enquanto um construto social formado na performatividade da interação (BUCHOLTZ, 1999; BUTLER, 1990; GAL, 1995) e também, de uma maneira mais ampla, do mundo social do qual somos parte de maneira integral e constitutiva. Com isso em mente, especificamente neste trabalho, analiso uma história de vida (LINDE, 1993) contada por uma professora, que se identifica como mulher cis lésbica, em uma relação de união estável.

Para tanto, a arquitetura teórica deste estudo fundamenta-se no conceito socioconstrucionista de identidade (BAUMAN, 2001, 2004; BUCHOLTZ, 1999; BUTLER, 1990; GIDDENS, 2002; HALL, 2000), entendendo as identidades como práticas identitárias coconstruídas discursivamente na interação, de forma situada historicamente e balizada por estruturas mais rígidas de viés ideológico (FOUCAULT, 1972). Em interface com os estudos de identidade, me alinho à epistemologia feminista (BULCHOLTZ, 1999; BUTLER, 1990, GAL, 1995; LYKKE, 2010), para entender como é coconstruída a identidade da participante com a analista no momento da entrevista com base no senso comum sobre características peculiares às relações homoafetivas, em oposição às relações heteroafetivas, e nos sistemas de coerência que regem os domínios da ciência e da informação para justificar seus posicionamentos. Para tal, trago como base para a análise da narrativa aqui trabalhada o conceito de história de vida da Linde (1993), juntamente ao seu entendimento de senso comum e sistemas de coerência.

Desse modo, podemos dizer que a relevância deste trabalho consiste em sua contribuição para a reflexão sobre a construção identitária de uma mulher lésbica em um relacionamento estável, mostrando empiricamente onde o senso comum e os sistemas de coerência aparecem no discurso da participante e como a influência desses construtos

Livre tradução minha. O mesmo vale para as demais citações extraídas de obras originalmente em inglês neste artigo.

pode se desdobrar na refutação ou, como neste caso, na imposição de seus predicados sobre os indivíduos, afetando suas narrativas de si e, consequentemente, a construção de 
suas práticas identitárias (BUCHOLTZ, 1999; BUTLER, 1990; GIDDENS, 2002; LINDE, 1993).

\section{2) Narrativa: socioconstrução de identidade, representação e história de vida}

Em tempos de modernidade líquida (BAUMAN, 2001), que reforça uma visão fluida (BAUMAN, 2004) e fragmentada de identidade (HALL, 2000), temos a exploração do corpo como lugar de vivência humana também por meio das construções discursivas que se centram na autobiografia do sujeito, que constrói a sua identidade por meio das narrativas sobre si, para assim formar uma identidade coerente (GIDDENS, 2002). Dentro dessa perspectiva, "indivíduos se tornam a narrativa autobiográfica por meio da qual contam sobre suas vidas" (RIESSMAN, 1993, p.2).

Entende-se, assim, a identidade como construto resultante de experiências mediadas (GIDDENS, 2002). Ao interagirmos uns com os outros em sociedade, criamos "pontos temporários de pertencimento" (HALL, 2000, p.19) que nos atrelam a posições de sujeito que práticas discursivas constroem para nós por meio do processo infindável da identificação, que "como toda prática significativa, é sempre sujeita ao 'jogo' da différance - [ou seja,] necessita trabalho discursivo, a dependência e a marcação de fronteiras simbólicas, a produção de "efeitos-de-fronteira" e precisa do que é deixado de fora, seu "constitutivo de fora" (constitutive outside), para consolidar o processo" (HALL, 2000, p.16).

Ainda nessa linha, Bauman (2004) vê a identidade como algo a ser inventado e não descoberto, como alvo de um esforço, um objetivo. Para ele, as identidades flutuam no ar, ora por nossa escolha, ora pela vontade dos outros, reconhecidas de maneira ambivalente e em negociação permanente, sem resultado fixo, mas que se traduz em "uma convenção socialmente necessária" que impõe dois polos gêmeos à existência social: "a opressão e a liberação" e é determinada por nosso "pertencimento ou não a diversas comunidades de ideias e princípios" (BAUMAN, 2004, p.13), que também podem ser entendidas como os sistemas de coerência e o senso comum apontados por Linde (1993), quando ela introduz sua conceituação de histórias de vida.

Nesse sentido, a identidade é um ponto de encontro, "um ponto de 'sutura' entre: i) discursos e práticas que procuram 'interpelar', falar conosco ou nos chamar aos nossos lugares de sujeitos sociais de discursos particulares, e ii) os processos que produzem subjetividades, que nos constroem como sujeitos que podem ser 'falados"' (HALL, 2000, p.19), o que nos traz à importância do estudo das narrativas como essencial quando buscamos entender como se dá a socioconstrução das identidades.

Ao entendermos a construção de nossas identidades nos termos supracitados, salientamos a importância de um indivíduo ter uma história de vida "coerente, aceitável e constantemente revisada" para que consiga "expressar seu senso de si" e entender quem é e como chegou onde está (LINDE, 1993, p.3). Nesse sentido, por meio do entendimento das histórias que contamos sobre nós mesmas/mesmos, tomamos também conhecimento de construções sociais mais abrangentes que regem nossas condutas éticas, morais e cotidianas por meio dos sistemas de crença que usamos para estabelecer coerência (LINDE, 1993). Desse modo, a análise de narrativas de histórias de vida como a que apresento neste trabalho, entendidas também como representação (RIESSMAN, 1993), 
se traduz como de extrema relevância na compreensão de como identidades são construídas para nós por nós mesmas/mesmos e/ou por nossos pares.

Dentro dessa lógica, ao escolher analisar a socioconstrução de identidades por meio das narrativas, devemos levar em consideração que quando estamos no processo investigativo de análise de discurso, inúmeras vezes iremos nos deparar com "o impulso natural de narrar" (RIESSMAN, 1993, p.3), presente nas práticas discursivas e sociais que permeiam as pesquisas qualitativas de conhecimento situado (HARAWAY, 1988). Mais ainda, podemos entender que as pessoas que participam das interações para geração de dados estão permanentemente em um processo de contar histórias (RIESSMAN, 1993), seja no momento da entrevista em si, quando se pode optar pela narrativização de "experiências de vida que representam uma quebra entre o ideal e o real, ou entre o si e a sociedade" (RIESSMAN, 1993, p.3), ou na hora da produção do texto da pesquisa propriamente dito. Assim, em consonância com os preceitos da LAC, podemos então focar em várias possibilidades de interpretação dessas narrativas que surgem nessas interações. Por exemplo, podemos buscar entender o porquê de uma dada história ser contada de uma dada maneira. Ou podemos ainda interpretar o que é dito para que entendamos quais identidades são construídas na interação e como as vidas das pessoas ali presentes são constituídas na performatividade da interação (BUTLER, 1990), uma vez que "agência e imaginação humanas determinam o que é incluído e o que fica de fora da narrativização, como eventos são tramados, e o que eles devem significar" (RIESSMAN, 1993, p.2). Esse último enfoque é o utilizado na análise deste trabalho.

Nesse contexto interpretativo, me apoio no conceito de narrativa como representação, cuja premissa é a impossibilidade de acesso à experiência do outro nas nossas interações, sendo possível o acesso somente às ambíguas representações que se dão nas experiências contadas (RIESSMAN, 1993, p.8). Dentro dessa lógica, penso a interpretação das narrativas com base nos cinco níveis do processo de pesquisa proposto por Riessman (1993). São eles: i) a apreensão da experiência (do inglês "attending the experience", tradução livre minha); ii) o contar; iii) o transcrever; iv) o analisar e v) a leitura da experiência (RIESSMAN, 1993, p. 10).

Cada um desses níveis tem sua própria relação com o fenômeno experienciado. No primeiro nível, a apreensão da experiência se dá pela seleção mental que fazemos quanto àquilo que reparamos, quando ativamente construímos a realidade de maneiras diferentes para nós mesmas/os. Em seguida, ao contarmos sobre a experiência, criamos significados pelo processo de interação em que criamos também a nós mesmas/os (GOFFMAN, 1959 apud RIESSMAN, 1993, p.11). No terceiro nível, o da transcrição, devemos atentar para as escolhas de convenção de transcrição e aceitar que, uma vez que exercermos escolhas constante e deliberadamente, a transcrição de discurso é sempre uma prática interpretativa, aproximada, nunca idêntica à realidade e que ela se dá de maneira incompleta, parcial e seletiva. Ou, como diz Garcez (2014, p.267), "não há transcrições perfeitas", mas, sim, "versões diferentes revisadas". No quarto nível, o da análise, valores, política e comprometimentos teóricos se tornam centrais nas escolhas e "uma metahistória é criada pela/o analista no intuito de dizer o que a narrativa significa, editando e redesenhando o que foi dito" (RIESSMAN, 1993, p.13). Por fim, no último nível, a/o leitor/a faz um trabalho colaborativo de interpretação com base em sua própria agência. Nesse sentido, e entendendo a linguagem como um sistema sociossemiótico de construção 
de significados, os textos são todos mutáveis e "plurivocais, abertos a diferentes leituras e a diversas construções" (RABINOW e SULLIVAN, 1979/1987³ apud RIESSMAN, 1993, p.14) a depender do contexto de cultura e de situação em que são produzidos (HALLIDAY e HASAN, 1989; HALLIDAY, 2004; HALLIDAY e MATHIESSEN, 2014). Assim, não podemos afixar uma única interpretação verdadeira às experiências narradas e nem, consequentemente, falar de maneira catedrática pelo outro (RIESSMAN, 1993).

Isto posto, neste artigo reitero que a grande contribuição desse trabalho de interpretação está exatamente em coconstruirmos os significados acerca de construtos de gênero, raça/etnia e classe social, na medida em que melhor entendemos como essas construções identitárias se dão discursivamente na interação. Assim, ao "deixar que símbolos representem a experiência primária, criando significados ambíguos que resultam da interação entre o si, a pessoa que conta, a que ouve, a que grava, a que analisa e a que lê" (RIESSMAN, 1993, p.15), habilitamos a possibilidade de investigarmos as construções que fazemos e, portanto, a nós mesmos. Outro ponto é que ao lidarmos com a linguagem como representação, enfatizamos as escolhas e a agentividade de cada uma das pessoas envolvidas no processo de interpretação da narrativização da experiência, que se consagra como uma metáfora da própria vida (RIESSMAN, 1993, p.17). Nesse sentido, a narrativa como representação nos serve de guia para as interpretações que fazemos da/na socioconstrução das identidades do indivíduo em sua busca pelo sentido de si, expressado de maneira constitutiva por meio das histórias de vida que conta, cujos ressignificados são coconstruídos em nossas interações sociais (LINDE, 1993).

Focando no conceito de narrativa como história de vida, identifica-se como história de vida "uma unidade descontínua, de reportabilidade alta, sujeita à revisão a cada vez que é retomada e pode ser determinada pela relação que tem com a identidade significante principal" (LINDE, 1993, p.4), podendo ser considerada ou não como um acidente (LINDE, 1993, p.6). De uma maneira geral, Linde (1993) resume uma história de vida como sendo:

Uma unidade oral que é dita em inúmeras ocasiões. Convencionalmente, ela inclui alguns tipos de eventos marcantes como a escolha profissional, casamento, divórcio, e conversões religiosas e ideológicas quando há. Tanto

\footnotetext{
RABINOW, P. e SULLIVAN, W. M. Interpretive Social Science: a second look. University of California Press, (1979)1987. p.12.

no conteúdo quanto na forma, ela é um produto de um membro de uma cultura particular (LINDE, 1993, p.11).
}

E acrescenta:

A história de vida é uma unidade linguística crucialmente envolvida na interação social (...) também relacionada com o nosso sentido interno, subjetivo de ter uma história de vida privada que organiza nosso entendimento de nossa vida pregressa, nossa situação atual, e nosso futuro 
imaginado. A história interna é acessível somente por introspecção (...) Apesar de ser extremamente difícil estudar essa história interna, estudar as histórias de vida públicas e coerentes revelam algo sobre o caminho pelos quais criamos nosso universo particular de significados (Linde, 1993, p.11).

Nesse sentido, a análise feita neste trabalho tem como intuito entender como a história de vida contada pela participante da pesquisa pode ser considerada uma espiadela em sua história interna (LINDE, 1993), no que diz respeito às identidades que ela clama para si e àquelas que são evocadas pela narrativa e pela interação, por meio dos significados que são construídos para ela e por ela.

Dos conceitos mais importantes para compreendermos as histórias de vida segundo LINDE (1993, p.12-18) estão: i) a ideia de que há uma "demanda social por coerência na interação", fazendo com que busquemos uma "sequência entre os acontecimentos significativa para as pessoas envolvidas na interação" e/ou uma "relação de causalidade" entre eles, mesmo que isso signifique que "quem ouve e quem fala tenham leituras diferentes do conteúdo da interação"; ii) a ideia de que quando analisamos histórias de vida "tudo o que podemos fazer é trabalhar com textos de um tipo ou outro" e não com verdades, irrelevantes para a análise uma vez que nos interessa como são construídos os significados em uma dada interação; iii) a ideia de que o processo de "correção social" se dá quando um indivíduo faz com que quem está narrando a história se reposicione quanto às crenças evocadas na troca interacional, reforçando o conceito do "discurso como socialmente construído ao invés de um fenômeno individualmente construído"; iv) o "senso comum" como fio condutor do pensamento e comportamento social, seja para refutá-lo ou abraçá-lo "de maneira consciente ou não" e os "sistemas de coerência" como "versões populares de teorias e sistemas de expertise específica", com os quais nos engajamos tanto social quanto culturalmente.

Neste trabalho, por possuir um olhar calibrado pela epistemologia feminista (LYKKE, 2010), foi importante observar os termos utilizados pela participante que representam o senso comum e/ou os sistemas de coerência (LINDE, 1993) que atravessam a narrativa.

\section{3) Princípios metodológicos e análise}

Uma vez que é um fenômeno social, um processo social com demandas sociais quanto à sua natureza (LINDE, 1993, p.7), as histórias de vida dependem não só do estado de espírito de quem conta a história, mas do grau de intimidade entre quem interage. Assim, o fato de eu conhecer a entrevistada foi um fator relevante quando montei as perguntas e quando aconteceu a entrevista/conversa de geração de dados.

À participante foi pedido que respondesse uma pergunta por escrito em que ela fazia o seu próprio perfil (ANEXO I). Com o perfil em mãos (ANEXO II), formulei perguntas de pesquisa (ANEXO III) para entrevistá-la. Meu objetivo era analisar como suas identidades eram construídas de maneira situada (HARAWAY, 1988) na performatividade de interação (BUCHOLTZ, 1999; BUTLER, 1990; GAL, 1995) por meio dos significados construídos discursivamente por suas escolhas léxico-gramaticais (HALLIDAY e HASAN, 1989; HALLIDAY, 1994) em narrativas de si (GIDDENS, 2002; RIESSMAN, 1993) que permeiam suas histórias de vida (LINDE, 1993), em 
congruência com a epistemologia feminista (LYKKE, 2010), mais especificamente sob o olhar do feminismo interseccional, que considera as questões de gênero necessariamente atreladas a questões de raça/etnia e classe social, tornando impossível o seu entendimento sem o acréscimo cumulativo dessas camadas de problematização (CRENSHAW, 1989; COLLINS, 1990; HOOKS, 1982).

Após a geração de dados pela entrevista, selecionei uma de suas histórias de vida: como ela conhecera sua esposa (LINDE, 1993). Essa narrativa é parte de um segmento de interação (GARCEZ, 2014) em que a participante se constrói socialmente em relação a questões de gênero e do qual foi feita uma análise micro/macro. O segmento tomou forma de um excerto ao ser transcrito de acordo com as convenções em anexo (ANEXO IV) (BASTOS e BIAR, 2015; GARCEZ, 2014). Os nomes citados no excerto são pseudônimos escolhidos por mim, obedecendo os parâmetros éticos e analíticos defendidos por Garcez (2014).

A história de vida aqui analisada é uma narrativa de representação (RIESSMAN, 1993) de como uma mulher, Tina, conheceu sua atual esposa, Giovana. A história é contada em resposta a uma pergunta feita por mim, analista, de maneira direta e objetiva, porém respeitando a coerência de assuntos que vinham sendo abordados na entrevista/conversa, no sentido de permitir que esta história de vida fosse contada de maneira mais natural possível.

O que torna relevante esta narrativa é o fato de ela ser uma narrativa de história de vida (LINDE, 1993) que é perpassada pelo senso comum (LINDE, 1993) do que é ter/ser uma família e das expectativas em torno um relacionamento entre lésbicas. Essa narrativa mais ampla é bastante reveladora da construção identitária que a participante reclama para si mesma, por meio das avaliações que ela inclui ao longo de toda a história narrada, buscando coerência discursiva para entender quem ela é no mundo e com o mundo (SOUZA, 2011). Outro ponto relevante nesta análise é a coconstrução da narrativa que se dá entre o que a participante conta e o que eu, analista, agrego de coerência para a história, buscando dar relações de sequência e causalidade às ações complicadoras que são contadas (LINDE, 1993).

\section{1) Contexto: "ah, essa menina aqui, muito bonita, me apresenta coisa e tal pá"}

A narrativa de vida analisada neste trabalho se dá após Tina contar o episódio específico de como ela conheceu sua esposa, Giovana (ANEXO V). Em uma narrativa canônica (LABOV, 1972), ela dá detalhes de como se deu o processo de enamoramento até a união em si. Em suma, Tina e Giovana terminaram com suas (hoje) ex-namoradas e em seguida a Giovana postou alguma coisa no Facebook®. Um amigo em comum, Patrício, curtiu o post, o que o deixou visível para a Tina, que fez um comentário ali, meio que despretensiosamente, segundo ela mesma. Ainda sob sua perspectiva, isso gerou interesse da Giovana, que começou a conversar com a Tina até elas logo se juntarem com as crianças, dando "tudo certo" por fim, já que as duas estão juntas até hoje, conforme a figura 1, linhas 17 e 18, abaixo (versão completa no ANEXO V). 


\section{2) Avaliações e Identidades: "para a relação sapatônica é um universo=é tipo bodas de diamante"}

As avaliações de Tina giram em torno das expectativas sociais que se tem sobre o comportamento "comum" (SACKS, 1984) em um primeiro encontro, seja online ou pessoalmente, e sobre a união de duas pessoas, no caso dela especificamente, duas mulheres. Ao contar a sua história de vida, Tina assegura o espaço interacional para trazer um episódio narrado de forma canônica que julga relevante na criação de si em relação à comunidade LGBT de que faz parte, à sociedade como um todo e a mim, interlocutora que tenta dar coerência ao que é contado por ela (GARCEZ, 2001, 2014; RIESSMAN, 1993; LABOV, 1972; LINDE, 1993).

Como vemos a seguir na figura 1 , no momento em que ela conclui a resolução do episódio (ANEXO V), ela começa a amarrar sua história a conceitos mais amplos que ideologicamente regulam as práticas sociais de uma mulher com seus atravessamentos (HOOKS, 1982; FAIRCLOUGH, 2001; FOUCAULT, 1972). Se por um lado ela vê a sua experiência como peculiar, como demonstra no trecho em anexo (ANEXO IV) pela forma como seu relacionamento começou (no Facebook®), ela reforça o senso comum de família, trazendo para a sua representação (RIESSMAN, 1993) a imagem da casa cheia (de crianças, de bicho de estimação) como positiva, quando diz "somos cinco e meio com o gato" (figura 1, linha 52).

Figura 1 - "para a relação sapatônica é um universo=é tipo bodas de diamante"

\begin{tabular}{|c|c|c|c|c|}
\hline 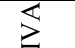 & 07 & Thais & a::í eu entendi aí vcs começaram [a se encontrar e tal & \\
\hline 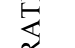 & 08 & Tina & [aí ela começou a conversar e tal. e a & Resolução \\
\hline 之 & 09 & & gente: se juntou com as crianças âh - tanto que a primeira vez que a & $\begin{array}{l}\text { Resolução / } \\
\text { Avaliação }\end{array}$ \\
\hline$\overleftrightarrow{a}$ & 10 & & gente se conheceu foi com todos os cri-filhos. & Avaliação \\
\hline 尝 & 11 & Thais & já foi todo mundo $\uparrow$ junto & $\begin{array}{l}\text { Coconstrução da } \\
\text { história }\end{array}$ \\
\hline Z出 & 12 & Tina & já foi todo mundo junto. aí: ela até brincou comigo depois falou... "esse aê & \\
\hline & 13 & & foi do dia que eu questionei se eu realmente queria entrar num & \\
\hline & 14 & & relacionamento com você." & \\
\hline & 15 & Thais & ((risos)) por quê? & \\
\hline & 16 & Tina & ((rindo)) porque aí foi aquela loucura ${ }^{\circ} \downarrow$ entendeu ${ }^{\circ}$ ? três crian::ças & Avaliação \\
\hline & 17 & & gritan::do brincan::do e coisa e tal. mas, deu tudo certo a gente tá junta & $\begin{array}{l}\text { Resolução / } \\
\text { Avaliação }\end{array}$ \\
\hline & 18 & & até $\uparrow$ hoje & $\begin{array}{l}\text { Resolução / } \\
\text { Avaliação }\end{array}$ \\
\hline & 19 & Thais & quanto tempo? & \\
\hline & 20 & Tina & faz dois anos mês que vem. já tem um tempinho [já. = & Avaliação \\
\hline & 22 & Thais & um tempinho bacana. e as crianças [são & \\
\hline & 22 & Tina & [= para a relação sapatônica é um & Avaliação \\
\hline & 23 & & universo.= & Avaliação \\
\hline & 24 & Thais & ((risos)) [é mesmo por quê?] & \\
\hline & 25 & Tina & [= é tipo bodas de diamante. & Avaliação \\
\hline & 26 & Thais & por quê? [não dura?] & \\
\hline & 27 & Tina & [porque eu não sei cara, eu posso ser- eu posso estar sendo & Influência do \\
\hline
\end{tabular}




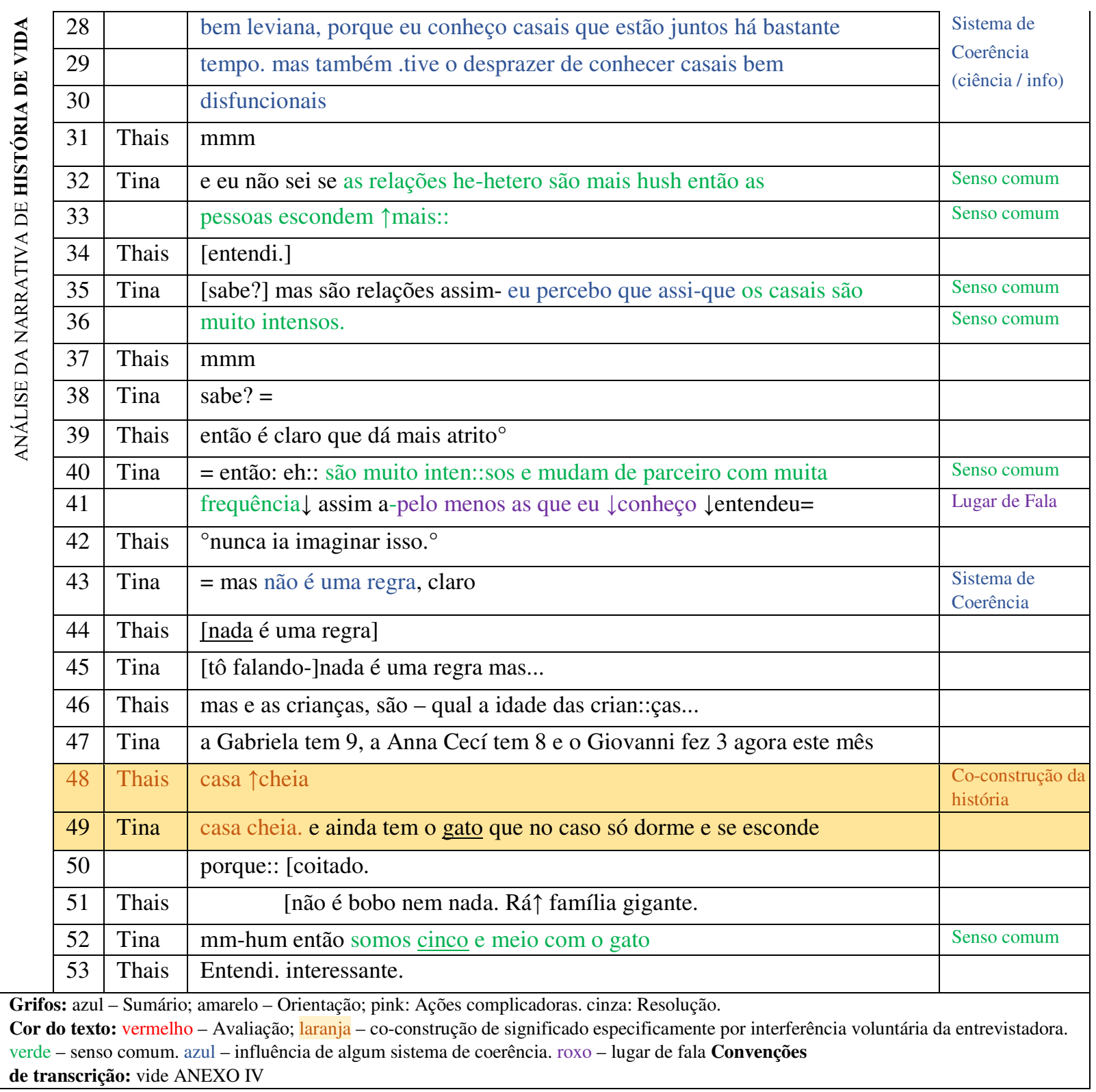

Aparentemente, Tina parece aderir ao senso comum quanto a lésbicas e outros membros da comunidade LGBT levarem suas vidas não dispostos a se comprometerem em um relacionamento estável ao afirmar que "os casais são muito intensos e mudam de parceiro com muita frequência" (figura 1, linhas 35, 36 e 40, 41), a colocando em um lugar especial em relação a seus pares, uma vez que ela está em um relacionamento estável. Até por isso acredito que ela opta por dizer "eu posso estar sendo bem leviana", admitindo ela mesma conviver com casais que "estão juntos há bastante tempo" mesmo que ela tenha tido "o desprazer de conhecer casais bem disfuncionais" (figura 2, linhas 27-30).

Ao restringir seu comentário à observação empírica dos fatos, reforçando a situacionalidade do que diz nas linhas 41 e 43 (figura 1 - "pelo menos as que eu conheço" [se encaixam na descrição dada] e "não é uma regra") percebe-se uma interferência do sistema de coerência do universo científico e da informação. Tina parece querer se respaldar por meio de um alerta de que o que ela diz tem a ver com o que ela vê, talvez em oposição a registros considerados mais confiáveis, como estudos científicos ou 
matérias jornalísticas. Nesse sentido, ainda assim prevalece o seu ponto de vista de quem vê os relacionamentos LGBT de dentro da comunidade, se posicionando como que consciente do seu lugar de fala (BENVENISTE, 1989), sendo ela lésbica, casada com uma mulher e, portanto, detentora de seu direito à experiência (SACKS, 1984).

Para justificar seu ponto de vista, Tina contrapõe relacionamentos homoafetivos aos heteroafetivos, acreditando que nos últimos os casais sejam mais reservados do que nos primeiros e escondam mais suas disfunções", ao dizer: "eu não sei se as relações hehetero são mais hush então as pessoas escondem mais" (figura 1, linhas 32 e 33).

Com essa história de vida, Tina constrói, na performatividade discursiva de nossa interação (BUTLER, 1990), sua identidade de mulher lésbica, casada e voltada para a família. Ao contar a sua história, Tina se ocupa em ser comum (SACKS, 1984), se mantendo dentro de parâmetros de normalidade do que se espera de relacionamentos que começam de maneira mais intensa e rápida (“foi aquela loucura, entendeu?", figura 1, linha 16) e dentro dos parâmetros reguladores determinados pelo senso comum, ao se colocar em total conformidade com o que é ser/ter uma família ("somos cinco e meio com o gato", figura 1, linha 52). Contudo, a partir de uma perspectiva posicionada e consciente de questões de gênero (GAL, 1995), Tina se constrói também como uma mulher de sorte dentro dos prospectos que o universo LGBT lhe resguarda em termos de relacionamento estável (que já dura dois anos) e de construção de família, o que "para a relação sapatônica é um universo=é tipo bodas de diamante", ainda que mais uma vez replicando estereótipos do senso comum (LINDE, 1993).

Pensando em como o senso comum opera em nossa concepção de mundo e em nossas crenças (LINDE, 1993), nesta história de vida aqui analisada, parece haver uma implicação de que o que Tina vive (um relacionamento estável) é impróprio ou inusitado pelo simples fato de ela ser uma mulher lésbica. Ao afirmar categoricamente que isso não é o esperado para alguém como ela, que ter tantos anos (dois) de relacionamento estável "para a relação sapatônica é um universo=é tipo bodas de diamante", sendo que ao longo de sua história ela valoriza a questão da família (tem o primeiro encontro já cercado de crianças, por exemplo), entendo que ela se coloca em um não-lugar, entendendo que subverte a lógica do que é esperado para ela inclusive pela sua própria comunidade.

Aprofundando um pouco mais a questão, Tina reforça ainda estereótipos e clichês típicos de dentro e fora da comunidade LGBT, como a ideia de promiscuidade entre os homens gays e descontrole emocional e psicológico das mulheres lésbicas (figura 1, linhas 38, 39 e 43, 44). Em uma ponte com um universo social mais amplo, para além da comunidade LGBT, ela apresenta uma visão essencialista da mulher como descontrolada emocionalmente e do homem como descontrolado sexualmente (sendo assim mais apto a trair e a procurar outras/os parceiras/os) ${ }^{5}$, típica da ideologia hegemônica de identidade de gênero, nos levando a cogitar que os valores heteronormativos são devidamente construídos e institucionalizados de maneira constitutiva na performatividade discursiva, influenciando diretamente na performance identitária feminina, seja qual for a leitura que

\footnotetext{
${ }^{1}$ Para entender exatamente o que Tina quis dizer nesse trecho foi necessário esclarecer com ela por meio de outro contato, dessa vez via mensagem de texto. Para ela, os casais heterossexuais não costumam "propagar ciúmes e paranóia" e "a coisa é mais discreta" (ANEXO VI). 
uma dada mulher faça de sua sexualidade, seu gênero, seu corpo e suas práticas sexuais (BUCHOLTZ, 1999; BUTLER, 1990; RUBIN, 1975).

\section{4) Considerações Finais}

Em sua história de vida (LINDE, 1993), Tina constrói sua identidade sob o viés social de questões de gênero. Ela se constrói na interação como uma mulher, lésbica, casada há um tempo, com filhos (e um animal de estimação), que transita entre as peculiaridades de seus atravessamentos de gênero e os compartilhamentos com o senso comum que rege o olhar social que temos sobre mulheres, lésbicas ou não.

A leitura sobre o encontro entre Tina e sua esposa carrega a possibilidade de construção identitária de Tina como uma mulher contemporânea, que faz uso de mídias sociais por meio das quais constrói relações e que demonstra sua inclinação a um relacionamento focado na construção de uma família nos moldes tradicionais de união (com um casal, filhos e bichos de estimação), em conformidade com o que se espera de uma mulher dentro do senso comum heteronormativo (BUTLER, 1990; RUBIN, 1975). Há ainda um certo grau de conformidade quanto a estereótipos associados à comunidade LGBT, apesar de ela falar com a propriedade de quem reivindica o seu lugar de fala (BENVENISTE, 1989) e o seu direito à experiência (SACKS, 1984), devido à sua perspectiva posicionada (GAL, 1995) quanto a questões de gênero. Em contrapartida a essas conformidades, Tina se considera "sortuda" por viver um relacionamento estável incomum a outros membros da comunidade LGBT, o que aponta para esse aspecto de sua identidade (ser casada há algum tempo) como algo contraditório às expectativas do senso comum.

Em suma, o resultado aqui descrito mostra um caminho para o entendimento das identidades como socioconstruídas na discursividade de maneira fluida, porém com a baliza de estruturas mais rígidas de regulamentação, ilustradas na representação do senso comum quanto a questões de gênero. Levando-se em consideração que esta análise é um recorte de uma pesquisa mais ampla de estudos da linguagem, que almeja melhor

\footnotetext{
Tina menciona isso mais profundamente na troca de esclarecimentos que se sucedeu à entrevista, quando explicando o que quis dizer sobre as disfunções de relacionamento homoafetivo e heterossexual introduzida na história ao dizer "eu não sei se as relações he-hetero são mais hush então as pessoas escondem mais" (figura 1, linhas 35 e 36).

compreender como se dá discursivamente a socioconstrução de identidade de professoras de inglês, dentro de uma perspectiva feminista interseccional, sua relevância está justamente em nos permitir apontar onde/como a construção identitária de uma mulher lésbica se dá no discurso, em suas contraditórias relações de conformidade e refutação do senso comum relativo às questões de gênero, para futuramente olhar para essa dinâmica em relação à sala de aula.
}

\section{Referências}

BASTOS, L.C.; BIAR, L. de A. Análise de narrativa e práticas de entendimento da vida social. DELTA. Documentação de Estudos em Linguística Teórica e Aplicada (PUCSP. Impresso), v. 31, p. 4, 2015. 
BAUMAN, Z. Modernidade líquida. Tradução: Plínio Dentzien. Rio de Janeiro: J. Zahar, 2001.

Identidade: entrevista a Benedetto Vecchi. Tradução: Carlos Alberto Medeiros. Rio de Janeiro: J. Zahar, 2004.

BENVENISTE, E. O aparelho formal da enunciação. In: Benveniste, E. (Ed) Problemas de Linguística Geral II. São Paulo: Pontes, 1989. p. 81-90.

BUCHOLTZ, M. Bad Examples: Transgression and progress in language and gender studies. In: Bucholtz, M. Liang, A. C.; Sutton, L.A. (Ed.), Susan e Thompson, Geoff (Ed). Reinventing Identities: The gendered self in discourse. Oxford University Press, 1999. p. 575-599.

BUTLER, Judith. Gender trouble: feminism and the subversion of identity. Londres/Nova Iorque: Routledge, Chapman e Hall, 1990.

COLLINS, Patricia Hill. Black feminist thought: knowledge, consciousness, and the politics of empowerment. New York: w York: Routledge, 1990.

CRENSHAW, K. Demarginalizing the Intersection of Race and Sex: A Black Feminist Critique of Antidiscrimination Doctrine, Feminist Theory and Antiracist Politics. The University of Chicago Legal Forum, vol. 1989, Issue 1, Article 8, 1989. p.139-167.

FAIRCLOUGH, Norman. Discurso e Mudança Social. Tradução: Izabel Magalhães. Brasília: Universidade de Brasília, 2001.

FERREIRA, A. J. Formação de Professores: raça/etnia: reflexões e sugestões de materiais de ensino em português e inglês. Cascavel: Gráfica Assoeste e Editora, 2006.

FOUCAULT, Michel. The archeology of knowledge. Tradução: A. M. Sheridan Smith New York: Pantheon Publications, 1972.

GAL, Susan. Language, gender and power: an anthropological review. In: Hall e Bucholtz (Ed.), Gender articulated: socially constructed self. Nova Iorque: Routledge, 1995. p.169-182.

GARCEZ, P. Deixa eu te contar uma coisa: o trabalho sociológico do narrar na conversa cotidiana. In: Telles Ribeiro, B.; Lopes Dantas, Maria (Org.) Narrativa, Identidade e Clínica. Rio de Janeiro: Edições IPUB/CUCA, 2001. p.189-214. 
GARCEZ, P.; BULLA, G.; LODER, L. Práticas de pesquisa microetnográfica: geração, segmentação e transcrição de dados audiovisuais como procedimentos analíticos plenos. D.E.L.T.A., Vol. 30.2, 2014, p.257-288.

GIDDENS, Anthony. Modernidade e identidade. Tradução: Plínio Dentzien. Rio de Janeiro: Jorge Zahar, 2002.

HALL, S. Who needs Identity? In: Gay, P. D.; Evans J. et alli. (Ed.) Identity: a reader. Londres: Sage/Open University Press, 2000. p. 15-30.

HALLIDAY, M. A. K. An Introduction to Functional Grammar. Londres: Arnold, 1994.

HAlliDAY, M. A. K.; HASAN, R. Language, Context, and Text. Aspects of Language in a Social-semiotic Perspective. Oxford: Oxford University Press, 1989.

HARAWAY, D. Situated Knowledges: The Science Question in Feminism and the Privilege of Partial Perspective. Feminist Studies, Vol. 14, No. 3. Autumn, 1988. p. 575-599

HOOKS, Bell. Ain't I a woman? London: Pluto Press, 1982.

LABOV, W. The transformation of the experience in narrative syntax. In: Labov, W. (Ed.) Language in the inner city: Studies in the black English vernacular. Philadelphia: University of Pennsylvania Press, 1972. p.354-396.

LINDE, Charlotte. Life Stories: the creation of coherence. Oxford University Press, 1993.

LYKKE, Nina. Feminist studies: a guide to intersectional theory, methodology and writing. Nova Iorque/Londres: Routledge, 2010.

RAJAGOPALAN, K. Repensar o papel da Linguística Aplicada. In: Moita Lopes, L. P. (Org.) Por uma Linguística Aplicada Indisciplinar. São Paulo: Parábola Editorial, 2006. p.149-168.

RIESSMAN, C. K. Narrative Analysis. Newbury Park: Sage Publications, 1993.

RUBIN, Gayle. Traffic in Women. Notes on the "political economy" of sex. In: Reiter, R. (Ed.), Toward an Anthropology of Women. Monthly Review Press, 1975. p. 157210 . 
PENNYCOOK, A. Uma Linguística Aplicada Transgressiva. In: Moita Lopes, L. P. (Org.) Por uma Linguística Aplicada Indisciplinar. São Paulo: Parábola Editorial, 2006. p.67-84.

Critical Applied Linguistics Challenges. ICCAL - International Congress of Critical Applied Linguistics. Brasília, 2015. Resumo disponível em: http://goo.gl/n3txuW

SACKS, H. On doing "being ordinary". In: ATKINSON, J. M. e HERITAGE, J. Structures of Social Action: Studies in Conversation Analysis. Cambridge, U.K.: Cambridge University Press, 1984.

\section{SILVA, K. A.; SANTOS, L. I. S.; JUSTINA, O. D. Entrevista com Kanavillil Rajagopalan: ponderações sobre linguística aplicada, política linguística e ensinoaprendizagem. Revista de Letras Norte@mentos - Revista de Estudos Linguísticos e Literários. Edição 08, Estudos Linguísticos, 2011/02. Disponível em: http://projetos.unemat-net.br/revistas_eletronicas/index.php/norteamentos}

SOUZA, L. M. T. M. Para uma redefinição de letramento crítico: conflito e produção de significação. In: Maciel, R. F.; Araújo, V. A. (Org.) Formação de professores de Línguas: ampliando perspectivas. Jundiai: Paco Editorial, 2011. p.128-140.

\section{ANEXOS}

\section{ANEXO I}

Olá, mulheres maravilhosas!!!

Estamos dando a largada ao nosso processo reflexivo sobre quem somos na nossa sala de aula, no nosso dia a dia, em relação a nossos colegas, nossos alunos, nós mesmas. Nosso primeiro desafio é TRAÇAR UM PERFIL de cada participante e para isso, conto com vocês. Assim, esta etapa é um convite para um exercício de pensar quem você é no contexto de suas relações pessoais e profissionais, no dia a dia das relações que permeiam a sala de aula.

A ideia é refletir sobre quem você é enquanto professora e mulher na sala de aula de inglês como língua estrangeira, pensando em termos de seus diversos atravessamentos identitários, dentre eles gênero, raça/etnia, classe social...mas não só; fique à vontade para incluir/excluir o que achar por bem. $\mathrm{O}$ objetivo aqui é que você diga o que acha importante/determinante sobre você, sua vida, suas práticas; o que deveria ser levado em consideração ao traçar seu perfil - uma espécie de "cartão de visita" para mim, para quem vai ler a pesquisa, para o mundo...

Ou seja, basicamente, pensem na pergunta: Como você se vê enquanto mulher e professora de inglês como língua estrangeira, em relação às práticas que atravessam a sala de aula, no seu contexto de vida e trabalho?

Sintam-se livres para escrever conforme preferirem: muito ou pouco, descrevendo exemplos pessoais ou não, falando de si e/ou de outros, contando casos, estórias, o que acharem por bem incluir para me ajudar a entender melhor vocês em relação aos contextos de vida/trabalho de cada uma. 
Para a gente não perder o fio da meada, vou pedir para vocês me enviarem o texto até domingo dia

$\underline{\mathbf{2 2} / \mathbf{0 5}}$, OK? Mas qq coisa, gritem!!!

Aguardo ansiosamente os textos de vocês!

Bjm para todaaaaaaasssssss

Thais Borges

\section{ANEXO II}

Título: nenhum (enviado no corpo do email)

Thais, queridona,

Vê se é isso que você tinha em mente. ;) Qualquer coisa se não tiver legal me avise, ok?

Ser professora é uma grande parte de mim como pessoa. Uma extensão, tipo braços e pernas então, quando estou na sala de aula é difícil fugir de quem eu sou para não entrar em assuntos polêmicos como homofobia, por exemplo.

Por mais que eu seja uma simples professora de inglês, sempre acreditei que um bom professor, de qualquer matéria que seja, tem como dever ajudar a formar cidadãos. Minha relação com meus alunos é sempre muito aberta e carinhosa então ás vezes me sinto uma farsa por ter que esconder alguns aspectos da minha vida pessoal. Acredito desde pequena que pessoas se apaixonam por pessoas; Independente de cor, credo ou gênero. E aconteceu comigo assim. Hoje, sou casada com outra mulher e divido com ela uma vida, filhos, contas. Assim como milhares de família por esse mundo afora. A diferença é que durante uma aula de família com meus alunos, por exemplo, eu não me sinto confortável apresentando o meu modelo de família.

Fico fossilizada naquele modelo tido como tradicional, temerosa de sair dos padrões e acabar tendo que arcar com uma série de consequências. Já tive alunos, que sofrendo por não se encaixarem nos padrões

impostos pela sociedade, buscaram minha ajuda e se surpreenderam com meu modelo de família, se sentiram acolhidos, talvez representados, não sei.

Rodei, rodei, mas o que eu realmente quis dizer é que estar fora da caixa que a sociedade tem como aceitável me faz ter um olhar mais carinhoso com meus alunos, especialmente os "diferentes". É como se a gente se olhasse e soubesse que somos parte do mesmo conjunto. Gosto de acreditar que eles olham pra mim e pensam: Vai ficar tudo bem.

Beijo!!!

\section{ANEXO III}

- Bom, primeiramente, conta pra mim como vc se tornou professora de inglês?

- Vc se define como "uma simples professora de inglês" - o que vc quis dizer com isso?

- Você menciona a importância de se formar "cidadãos" por meio da educação - oq isso significa pra vc?

- Vc fala do seu modelo de família. Como ve descreve sua família? Vc pode falar um pouquinho da história de vocês? 
- Vc se coloca como alguém "fora da caixa que a sociedade impõe como aceitável" - como vc explica isso?

- E na sala de aula, vc diz que é difícil fugir de quem vc é para fugir de assuntos polêmicos como a homofobia, por exemplo - como vc lida com isso? Vc se lembra de algum episódio?

- Por outro lado, vc diz que se sente "uma farsa" ao esconder assuntos de sua vida pessoal - como exatamente isso se dá? Vc se lembra de algum momento específico que isso tenha rolado na sala de aula?

- E em relação a outros teachers, outras pessoas da escola em que trabalha, como vc vê essa questão? Vc se lembra de algum momento de estresse por conta disso?

- Vc acha que existem duas personas (CONCEITUAR $\gg$ > Martin? White?): a Tina pessoa $\mathrm{X}$ a Tina professora?

- Em relação aos alunos, vc diz que se identifica com os diferentes - como vc descreve esses "diferentes" e essa identificação com eles?

- Vc diz que gosta de pensar eu eles te vêem e pensam "vai ficar tudo bem" - Como vc acha que isso se dá? Vc é otimista em relação a isso?

- Vc se lembra de algum momento crítico que tenha vivido em sala de aula em relação a questões de gênero, raça/etnia é ou classe social? O que o tornou crítico? Como você lidou com ele? Quais foram os desdobramentos? Como você teria lidado de maneira diferente?

\section{ANEXO IV}

\begin{tabular}{|cl|}
\hline Convenções de Transcrição & \\
$\ldots$ & pausa não medida \\
entonação descendente ou final de elocução & entonação ascendente \\
$?$ & entonação de continuidade palav- marca \\
corte abrupto & \\
$=$ & elocuções contíguas, enunciadas sem pausa entre elas \\
Sublinhado/ bold & ênfase \\
\hline opalavra ${ }^{\circ}$ & palavra em voz baixa \\
(inaudível) & impossibilidade de detectar o que foi dita \\
\hline$:$ ou :: & alongamentos \\
[ & início de sobreposição de falas \\
] & final de sobreposição de falas \\
() & fala não compreendida \\
$(())$ & comentário do analista, descrição de atividade não verbal \\
“palavra" & fala relatada, reconstrução de um diálogo \\
$(($ risos) $)$ & riso \\
$\uparrow$ & subida de entonação \\
$\downarrow$ & descida de entonação \\
& BASTOS e BIAR (2015), GARCEZ (2014) \\
&
\end{tabular}

\section{ANEXO V}

Narrativa Canônica - "ah essa menina aqui, muito bonita, me apresenta coisa e tal pá"

\begin{tabular}{|l|l|l|l|}
\hline 1 & Thais & então mas como ves se conheceram na verdade? coméque é sua história & $\begin{array}{l}\text { História de vida } \\
\left(1^{a} \text { encontro } \mathrm{c} /\right. \\
\text { esposa })\end{array}$ \\
\hline
\end{tabular}




\begin{tabular}{|c|c|c|c|}
\hline 3 & Tina & eu conheci a Giovana - na verdade a Giovana é u- é uma história bem & $\begin{array}{l}\text { Sumário } \\
\text { /Avaliação }\end{array}$ \\
\hline 4 & & bem interessante. eu tinha uma $\mathbf{e x}$, namorada que:: me apresentou um & Orientação \\
\hline 5 & & grande amigo meu que é o Patrício. e aí a gente passou o carnava & Orientação \\
\hline 6 & & juntos e tal $\downarrow$ e o Patrício é amigo da Giovana desde: a infância assim & Orientação \\
\hline 7 & & 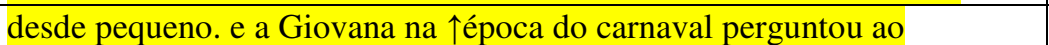 & Orientação \\
\hline 8 & & Patrício "ah essa menina aqui, muito bonita, me apresenta coisa e tal pá" & Orientação \\
\hline 9 & & aí o Patrício falou "não ela tá namorando e::" vida que segue. e aí, eh:: & Orientação \\
\hline 10 & & nessa coisa de $\uparrow$ facebook, ela no facebook dele quando eu terminei com & $\begin{array}{l}\text { Ação Comp. } \\
\text { /Avaliação }\end{array}$ \\
\hline 11 & & a minha ex eh:: ela postou alguma coisa no facebook e eu lembro que eu & $\begin{array}{l}\text { Ação } \\
\text { Complicadora }\end{array}$ \\
\hline 12 & & $\uparrow$ comentei, e aí a gente começou a conversar no facebook e:: & $\begin{array}{l}\text { Ação } \\
\text { Complicadora }\end{array}$ \\
\hline 13 & Thais & $\uparrow$ oh & \\
\hline \multirow[t]{21}{*}{14} & Tina & Péo & \\
\hline & & & $\begin{array}{ll} & ! "\end{array}$ \\
\hline & & foi foi primeiro online. & $\begin{array}{c}\% " \\
\#\end{array}$ \\
\hline & & !)! \# \& ${ }^{*}+$ & \\
\hline & & $+!$ & $\% \&$ \\
\hline & & $! \quad ! \quad !$ & $\% \&$ \\
\hline & & )$! !$ & \\
\hline & & )! ' !\#!+ // !\#0\& 11 & \\
\hline & & $2 !+$ & $\begin{array}{l}\% " \\
\# "\end{array}$ \\
\hline & & $+\&) !$ & \\
\hline & & +4 + 7 \# & $\begin{array}{l}\% " \\
\#\end{array}$ \\
\hline & & $1 \quad 8 \#$ & $\begin{array}{l}\% " \\
\#\end{array}$ \\
\hline & & !!! $\quad / / 2$ & \\
\hline & & 11 & \\
\hline & & $1 \quad !: !$ & $\begin{array}{cc}\% \& & \text { "4; } \\
\% " & \\
\# & \end{array}$ \\
\hline & & $\& \quad ! \quad) !$ & $\begin{array}{l}\text { \%" } \\
\#\end{array}$ \\
\hline & & $\&+$ & $\begin{array}{l}\text { \%" } \\
\#\end{array}$ \\
\hline & & $+\& 9$ & \\
\hline & & $\$ * * \#+$ & \\
\hline & & $+\quad) !$ & $\begin{array}{l}\text { \%" } \\
\#\end{array}$ \\
\hline & & $=?$ & \%" \\
\hline
\end{tabular}




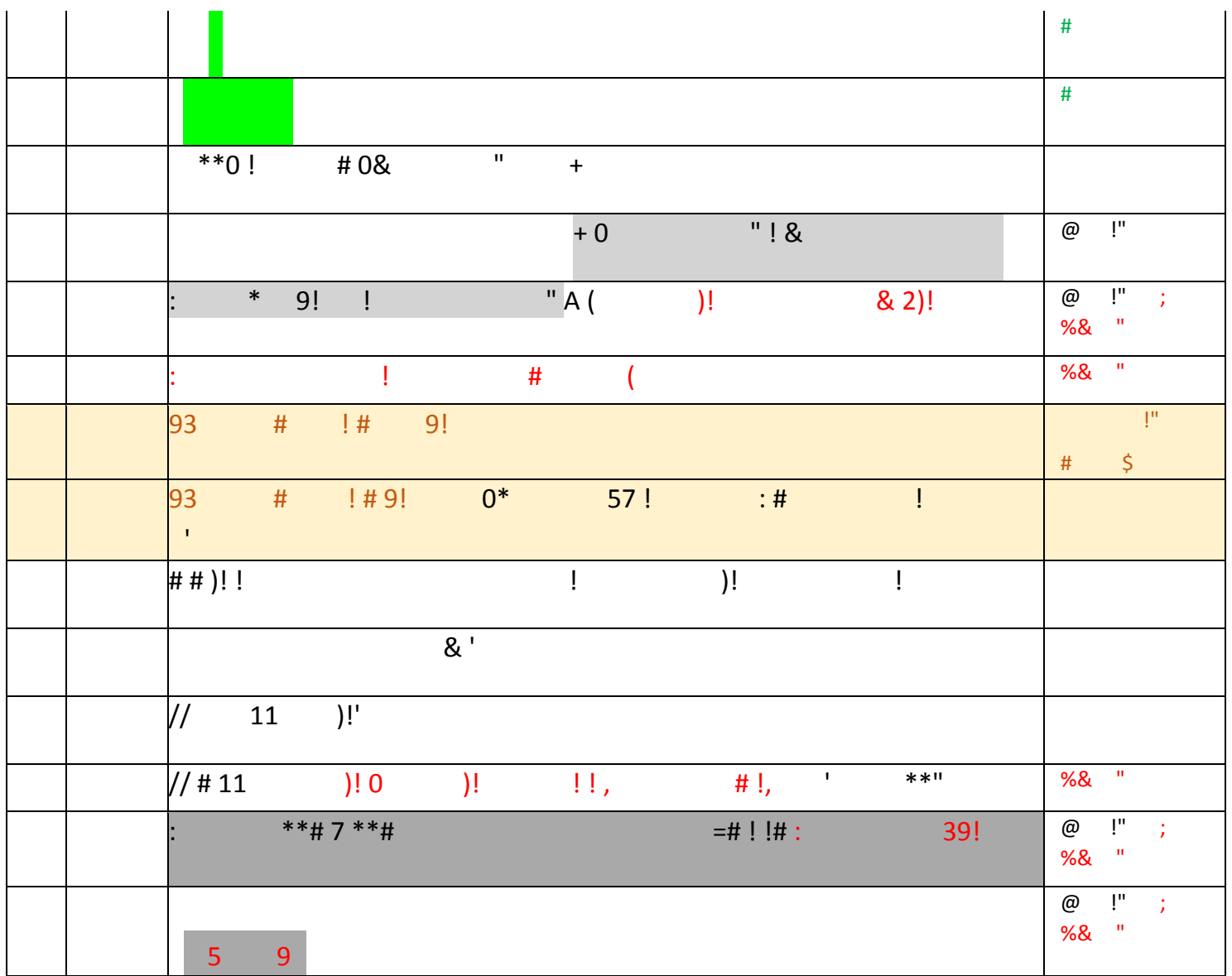

Grifos: azul - Sumário; amarelo - Orientação; pink: Ações complicadoras. cinza: Resolução.

Cor do texto: vermelho - Avaliação; laranja - co-construção de significado especificamente por interferência voluntária da entrevistadora. verde - senso comum. azul - influência de algum sistema de coerência. roxo - lugar de fala Convenções de transcrição: vide ANEXO IV 


\section{ANEXO VI}

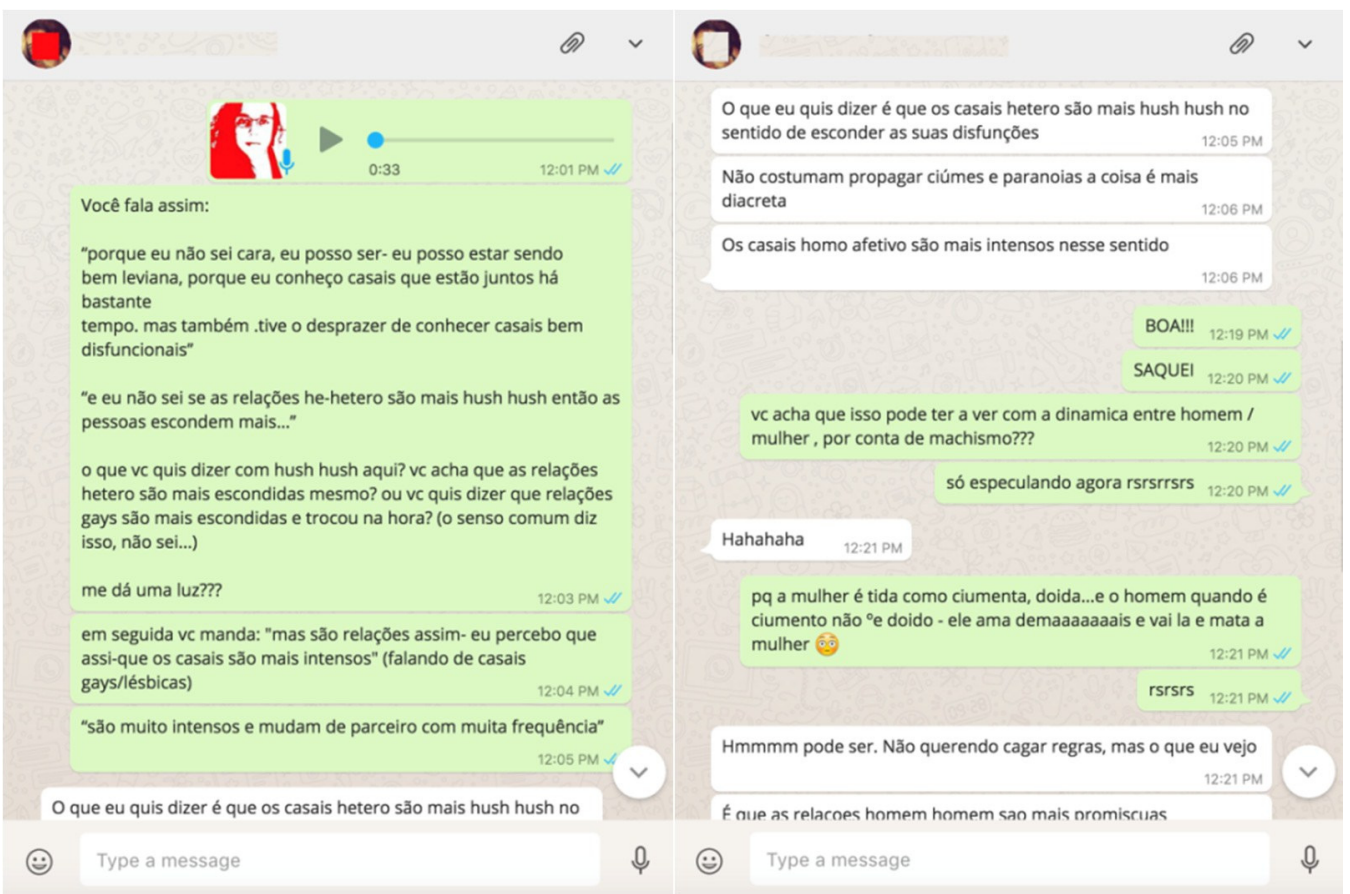

Hmmmm pode ser. Não querendo cagar regras, mas o que eu vejo

É que as relaçoes homem homem sao mais promiscuas

$12: 24 \mathrm{PM}$

Mas as de mulher $\mathrm{x}$ mulher sao mais intensas e tem mais a coisa da agressao fisica por exemplo

Pelo menos as que eu tenho contato 